\title{
О Терминологии Программной Инженерии
}

\author{
Сайяр Абдуллаев ${ }^{1}$, Сабина Фоменко ${ }^{2}$ \\ ${ }^{1,2}$ Институт Информационных Технологий НАНА, Баку, Азербайджан \\ ${ }^{1}$ depart5@iit.science.az, ${ }^{2}$ sabina.fomenko@gmail.com
}

\begin{abstract}
Аннотация- В настоящей статье даётся информация о появлении термина «программная инженерия», дается краткая информация о словаре по системной и программной инженерии, а также рассматривается стандартный глоссарий терминов по программной инженерии.
\end{abstract}

Ключевые слова- программная инжсенерия, IЕEЕ, IЕEЕ Standard 610-90, терминология, глоссарий, ISO, SEVOCAB, ISO/IEC 12207, ISO/IEC 15504, ISO 9001, ISO/IEC FDIS 24765

\section{I. ВВЕДЕНИЕ}

Стремительный рост потенциала и снижение затрат современных информационных технологий открывают большие возможности в образовании новых форм труда как в отдельных организациях, так и в обществе в целом. Виды таких возможностей становятся шире и воздействуют на все вокруг: на жизнь людей, на их семью, на образование и работу и т.д. На сегодняшний день информационные технологии вносят значительный вклад в укрепление взаимосвязей между ростом производительности труда, объемами производства, инвестициями и занятостью. Практика последних лет, показывает, что по всем сетям распространяются новые виды услуг, что является причиной создания немалого количества рабочих мест.

В начале 1940-х годов в период появления первых современных цифровых компьютеров наборы исполняемых им команд уже заранее встраивались в машину. Вскоре стало ясно, что такой подход не совсем удобен. Это привело к появлению «архитектуры хранимых программ» или архитектуры фон Неймана. Абстракция используемая для решения проблем сложности вычислений положила начало разделению на программное и аппаратное обеспечение [1].

Программную инженерию можно ассоциировать с разработкой коллективами разработчиков сложных и больших по объему программ.

Первый кризис программирования произошел в конце 60-х - начале 70-х годов. Причиной кризиса послужило то, что стоимость аппаратуры и стоимость программного обеспечения практически приравнялась. Динамика роста этих стоимостей позволяла предполагать, что к середине 90-х годов все будут заниматься разработкой компьютерных программ. Именно в этот период технология промышленного программирования или программная инженерия стала рассматриваться как некоторая дисциплина целью, которой является сокращение стоимости программ [2]. Стого времени программная инженерия получила значительныеэтапы развития. Каждый из этих этапов имеет свои характерные свойства и связан с какой-либо проблемой и нахождением путей решения этих проблем.

В настоящее время в области программной инженерии используется множество терминов. Каждый из терминов,со стороны разработчиков программного обеспечения,может пониматься неоднозначно. По причине того, что по сравнению с другими областями инженерии программная инженерия до сих пор остается относительно молодой вокруг нее появляется множество вопросов.

\section{II. ТЕРМИН ПРОГРАММНАЯ ИНЖЕНЕРИЯ}

Программная инженерия проникла во все сферы современной жизни людей. С каждым днем она все больше развивается и становится более практичной.

Программная инженерия является относительно молодой областью исследования, её теоретические основы по сравнению с другими развитыми отраслямиразработаны не очень глубоко. По этой причине исследования, проводимые в этой областииспользуют знания, которые накоплены в связанных с ней дисциплинах.

В октябре 1968 года на конференции по науке и технике (г. Гармиш, Германия) проводимой подкомитетом НАТО впервые был озвучен термин softwareengineering (программная инженерия). На конференции присутствовало 50 профессиональных разработчиков программного обеспечения из 11 стран и рассматривались проблемы проектирования, распространения, разработки и поддержки программ. Там впервые термин «программная инженерия» был представлен как некоторая дисциплина, которую надо создавать, и которой надо руководствоваться при решении перечисленных проблем [2].

\section{III. ОСНОВНЫЕ СТАНДАРТЫ ПРОГРАММНОЙ ИНЖЕНЕРИИ}

Информационные системы представляют собой важную, стремительно развивающуюся инфраструктуру. В успешном развитии, а также и в эффективном применении информационных систем стандартизация является одном из ключевых моментов. При этом важное место занимают стандарты программной инженерии, которые устанавливают правила, общие принципы, процессы инструменты для создания эффективных программных средств.

Стандарты программной инженерии активно развиваются, как за счет совершенствования официальных 
международных стандартов программной инженерии, так и за счет формирования набора фактически существующих стандартов.

Существуют международные (ISO), профессиональные (IEEE), национальные (например, австралийские или британские) и относящиеся к конкретным сферам профессиональной деятельности стандарты программной инженерии. Среди этих стандартов можно выбрать подходящие к конкретной ситуации.

Существует несколько основных стандартов относящиеся к процессам программной инженерии:

- ISO/IEC 12207:2008 Systems and software engineering - Software lifecycle processes - стандарт, описывающий процессы жизненного цикла программного обеспечения [3];

- ISO/IEC 15504, Software Process Assessment (multipart), 1998;

- ISO 9001, Quality Management Systems-Requirements, 2015.

На сегодняшний день стандарты, которые основывают программную инженерию, включают в себя как словарь, так и ряд общих руководств. ISO/IEC FDIS 24765: 2010 является проектом словаря программной инженерии. Последний его вариант был пересмотрен и подтвержден в 2016 году. В основу словаря положен глоссарий терминов в области программной инженерии IEEE 610.121990,основные стандарты системной и программной инженерии, включая ISO/IEC15288:2008 и ISO/IEC 12207:2008, известное семейство ИТ-словарей ISO/IEC 2382 и ряд других спецификаций[4].

Словарь называется SEVOCAB: Software and Systems Engineering Vocabulary[5]. C его помощью можно найти определения терминов используемых при разработке программного обеспечения. Введя в поисковую строку этого словаря искомое слово, можно получить значение этого термина как в одном стандарте, так и а во всех стандартах.

Общие руководства по программной инженерии можно разделить на три группы спецификаций: руководства, определяющие принципы описания объектов и процессов программной инженерии, руководствам к сводам знаний в области программной инженерии, а также руководства по сертификации специалистов[4]. В таблице 1 приведена краткая характеристика этих документов.

\section{IV. СТАНДАРТНЫЙ ГЛОССАРИЙ ТЕРМИНОВ ПО ПРОГРАММНОЙ ИНЖЕНЕРИИ}

Как и во всех сферах, так и в программной инженерии используются присущие ей термины. Очевидно, что если разработчики не будут одинаково понимать термины, то написание и понимание программного обеспечения будет невозможно. При этом возникает множество спорных вопросов в терминологии программной инженерии. Для решения этих проблем был разработан стандартный глоссарий терминов по программной инженерии.
ТАБЛИЦА 1. КРАТКАЯ ХАРАКТЕРИСТИКА ДОКУМЕНТОВ РУКОВОДСТВ

\begin{tabular}{|c|c|c|}
\hline \multicolumn{3}{|c|}{ Программная инженерия Основы } \\
\hline \multicolumn{3}{|c|}{ Словари и Тезаурусы } \\
\hline \multicolumn{3}{|c|}{ Словарь -.ISO/IEC FDIS 24765} \\
\hline \multicolumn{3}{|c|}{ ОБЩИЕ РУКОВОДСТВА } \\
\hline Принципы описания & Своды знаний & $\begin{array}{c}\text { Сертификация } \\
\text { специалистов }\end{array}$ \\
\hline $\begin{array}{l}\text { 1). ISO/IEC } \\
42010: 2011 \text { - } \\
\text { устанавливает основы } \\
\text { для архитектурного } \\
\text { описания } \\
\text { программно- } \\
\text { интенсивных систем } \\
\text { и используя } \\
\text { концепции связанные } \\
\text { с различными } \\
\text { точками зрений на } \\
\text { систему и } \\
\text { соответствующие } \\
\text { представления } \\
\text { определяет его } \\
\text { содержание. } \\
\text { 2). ISO/IЕC ТR } \\
24774: 2010- \\
\text { используя } \\
\text { характеристики целей } \\
\text { процесса, его } \\
\text { результатов, } \\
\text { выполняемых } \\
\text { действий и работ } \\
\text { устанавливает общие } \\
\text { правила при } \\
\text { построении } \\
\text { эталонных моделей } \\
\text { процессов } \\
\text { жизненного цикла. }\end{array}$ & $\begin{array}{l}\text { ISO/IEC TR } \\
\text { 19759:2015 - это } \\
\text { руководство } \\
\text { (SWEBOK), которое } \\
\text { определяет и } \\
\text { описывает области } \\
\text { знаний, которые } \\
\text { должен знать } \\
\text { программный } \\
\text { инженер. }\end{array}$ & $\begin{array}{l}\text { ISO/IEC } \\
24773: 2008- \\
\text { устанавливает } \\
\text { общие принципы, } \\
\text { которые } \\
\text { используются при } \\
\text { сравнении схем } \\
\text { сертификации, } \\
\text { которые содержат } \\
\text { требования к } \\
\text { специалистам по } \\
\text { программной } \\
\text { инженерии. } \\
\text { ISO/ІЕС NР } 29154 \\
\text { - это руководства } \\
\text { и примеры по } \\
\text { сертификации } \\
\text { специалистов по } \\
\text { программной } \\
\text { инженерии. }\end{array}$ \\
\hline
\end{tabular}

Данный глоссарий был создан Институтом инженеров электротехники и электроники (IEEE - Institute of Electrical and Electronics Engineers). IEEE Standard 610-90 (Standard Glossary of Software Engineering Terminology) является последней инстанцией разрешения споров по терминологии в программной инженерии [6].

IEEE - это международная некоммерческая ассоциация специалистов в области техники, мировой лидер в области разработки стандартов по радиоэлектронике, электротехники и аппаратному обеспечению вычислительных систем и сетей [7].

Стандартный глоссарий терминов по программной инженерии определяет термины, используемые в настоящее время в области программной инженерии. В нем установлены стандартные определения этих терминов.

Как и документация всех стандартов IEEE,так и документация IEEE Standard 610-90 разрабатывается Техническим Комитетом Общества IEEE и Координационным Комитетом Стандартов Совета по Стандартам IEEE [8].Члены этих комитетов работают в качестве волонтеров. Стандарты, разработанные в рамках IEEE, являются общепринятыми решениями Института инженеров электротехники и электроники и других организаций, которые заинтересованы в разработке стандартов. 
Последняя версия стандартного глоссария терминов по программной инженерии была создана в 1990 году.

Как и все стандарты IEEE стандартный глоссарий терминов по программной инженерии пересматривается или подтверждается, как минимум один раз в пять лет. В связи с этим обязательно нужно пользоваться последней версией стандартного глоссария.

Использование IEEE Standard 610-90 - стандартного глоссария терминов по программной инженерии является полностью добровольным. Существование данного стандарта не подразумевает, что нет других способов производить, тестировать, измерять, покупать, продавать или предоставлять другие товары и услуги, связанные с областью его применения. Кроме того, точка зрения, выраженная в момент утверждения и выпуска глоссария, может быть изменена в результате изменений полученных от его пользователей[8].

\section{ЗАКЛЮЧЕНИЕ}

Сфера применения компьютеров продолжает расширяться. Новые термины создаются и принимаются на существующих условиях. Для документирования этой лексики и был создан стандартный глоссарий терминов по программной инженерии. Целью его создания являлось: определить термины, используемые в настоящее время в компьютерной области, и установить стандартные определения этих терминов. Словарь призван служить полезным справочным пособием для тех, кто находится в компьютерной сфере, и для тех, кто вступает в контакт с компьютерами, будь то в своей работе или в повседневной жизни.

В настоящее время создаются интегрированные системы международных фактических и официальных стандартов программной и системной инженерии. В этом процессе участвуют все официальные международные и наиболее известные мировые профессиональные организации стандартизации; официальные и профессиональные организации (выделяются IEEE, INCOSE, PMI, OMG) стандартизации, в том числе и организации, которые заняты проектами создания электронных правительств активно участвуют в этой работе [10].

\section{ЛИТЕРАТУРА}

[1] Информационные технологии:, http://ru.wikipedia.org/wiki/Информационные_технологии

[2] С.Н. Карпенко, «Введение в программную инженерию», Нижний Новгород, стр. $4-6,2007$.

[3] ISO/IEC 12207:2008:, https://ru.wikipedia.org/wiki/ISO/IEC_12207:2008

[4] В.К. Батоврин, «Современное состояние международных стандартов системной и программной инженерии», Бизнес-информатика №3(09), 2009, стр. 5 - 9 .

[5] Software and Systems Engineering Vocabulary: https://pascal.computer.org/sev_display/printCatalog.action

[6] Программная инженерия:,http://glebradchenko.susu.ru/courses/bachelor/engineering/2 $016 /$

[7] Институт инженеров электротехники и электроники:, http://ru.wikipedia.org/wiki/Институт_инженеров_электротехники_и_ электроники

[8] IEEE Standard Glossary of Software Engineering Terminology, The Institute of Electrical and Electronics Engineers September 1990. 